\title{
Experimental analysis of the noise produced by burners inside a boiler plant in an educational building
}

\author{
Catalin Bailescu, Vlad Iordache \\ Technical University of Civil Engineering of Bucharest, Romania \\ 124 Bdul Lacul Tei, Bucharest, 020396 \\ E-mail: catalin.bailescu@gmail.com \\ E-mail: viordach@yahoo.com
}

\begin{abstract}
One of the most important parameters of comfort in a building is acoustic comfort for which designer engineer typically given little or no attention during project planning and design. The purpose of this article is to highlight the noise produced by boilers in a technical room of a faculty in Romania. Different measurements were performed for the gas flow and noise level in the boiler room. The measurements resulted in several values of the noise level for different thermal loads of the boilers. The result obtained confirm that noise level depends on the thermal load and that increase of thermal load is directly proportional to the noise level inside the plant room. After the measurements, the values of the noise level were processed and compared with literature predicted values and the maximum limit values from the Romanian norm. The results of this article highlighted the noise produced in a technical space of a modern power plant, correctly installed and calibrated. This study can by used by design engineers and all participants in designing and installing equipment in a new educational building, but also in an existing building to meet the comfort conditions of the students.
\end{abstract}

Key words: acoustic comfort, noise level, faculty, measurements, boiler plant

\section{Introduction}

Beside the already recognized indoor comfort categories (thermal, illumination, pollution), the acoustic comfort becomes an increasingly important aspect nowadays both nationally and internationally.

As a result, national standards have been adopted in several countries by setting maximum noise levels for different environments. These standards vary from one country to another and in the United States have been imposed in the form of recommendations [3], guidelines [4] or statutory requirements [5]. In the European Community the limits of noise level are imposed by mandates regulations of noise exposure [6] and noise evaluation standard [7].

In Romania, the acoustics norm in constructions and urban areas [8] prescribes admissible limits established considering the appropriate climate specific to the use and the indoor destination of the space.

Because road traffic noise is considered the main source of loss of environmental and life in a metropolis [10] much of previous studies on acoustic comfort has been 
Catalin Bailescu, Vlad Iordache

focused on road, rail, and air traffic [11-13]. However achieving acoustical comfort in buildings, it is not just about reducing this type of noise, because in several previous studies [14-15] has been reported that in residential building an important source of acoustic discomfort is noise from boiler plant. The noise prediction from technical room is an important consideration in the design stage, operation, and construction of all buildings.

In [9] two methods of predicting the noise level in the technical spaces are proposed. The first model [1] established by Cyssau in 1997 shows a formula established following a study of a 145 database of thermal power plants under $16 \mathrm{MW}$ designed to present the relationship between the noise level of thermal power plants and their thermal power:

$\mathrm{L}_{p}=10 \cdot \log _{10}(\mathrm{P})+55$

where:

$\mathrm{Lp}, \mathrm{dB}$, is sound pressure level and

$\mathrm{P}, \mathrm{kW}$, is real thermal power for 60 seconds.

This prediction model is characterized by a 10 [dBA] error. Another method [2] predicts the noise level inside thermal plants as a function of both the thermal power and the volume of the thermal plant:

$\mathrm{L}_{\mathrm{p}}-16 \log \mathrm{Q}-10 \log \mathrm{V}+54[\mathrm{dBA}]$

which is characterized by a $5[\mathrm{dBA}]$ error, and where:

$\mathrm{Lp}, \mathrm{dB}$, is sound pressure level

$\mathrm{Q}, \mathrm{kW}$, is the real thermal power for 60 seconds,

$\mathrm{V}, \mathrm{m}^{3}$, is the room volume.

These noise prediction models are characterized by large errors and rises questions regarding their suited for today's thermal equipment. In this analysis we will analyse if these models are adapted to today's boiler plant equipment or it is necessary to create a new prediction model of noise level for design stage.

The study follows an experimental approach. Simultaneous measurements of thermal power and the noise level were recorded in order to understand the relationship between the noise level and the thermal power generated inside the thermal plant. The noise level ware recorded for different operation status of the boilers (different thermal loads) and was compared to the value required by Romanian norm [8] and the prediction methods [1],[2].

The paper presents the experimental results of noise level inside one a technical room, the recordings database, results, and discussions. 
Experimental analysis of the noise produced by burners inside a boiler plant in an educational building

\section{Experiments}

The measurements were carried out by a team of three people: one person registers the gas index, another one operates the boiler automation, and the third person carries out the noise measurements.

The analysed thermal plant is a stand-alone building located on demi basement of a Faculty of Geodesy of Technical University of Construction (Fig.1a) in Bucharest town, Romania. It has a $4.8 \mathrm{MW}$ thermal power capacity and serves a group of five faculties and annexes.

The thermal plant room is rectangular shaped (dimensions: $12.46 \mathrm{~m}$ long, $10.96 \mathrm{~m}$ wide and $4.84 \mathrm{~m}$ height, volume $660.96 \mathrm{~m}^{3}$.) (Fig.1c). The walls of the boiler plant are made of brick, hardwood, and the tiled floor. Hard surfaced of this boiler room will have a longer reverberation time than rooms finished with sound absorbing materials. The immediate effect of multiple reflections is an increase in the sound intensity caused by the reflections. A fireman will hear the direct sound arriving at the ear along with all of the multiple sound wave reflections.

The thermal plant has three 1480KW Prextherm RSW and one 399KW Prextherm RSW. The burners of these boilers are of the RBL type RS190 with two power stages of 470-2290KW, respectively RBL type R38 with two power stages of $105-440 \mathrm{KW}$ In the boiler assembly we find 12 Grundfoss pumps MG90LA4, two heat exchangers with plates, 2 buffer tank.
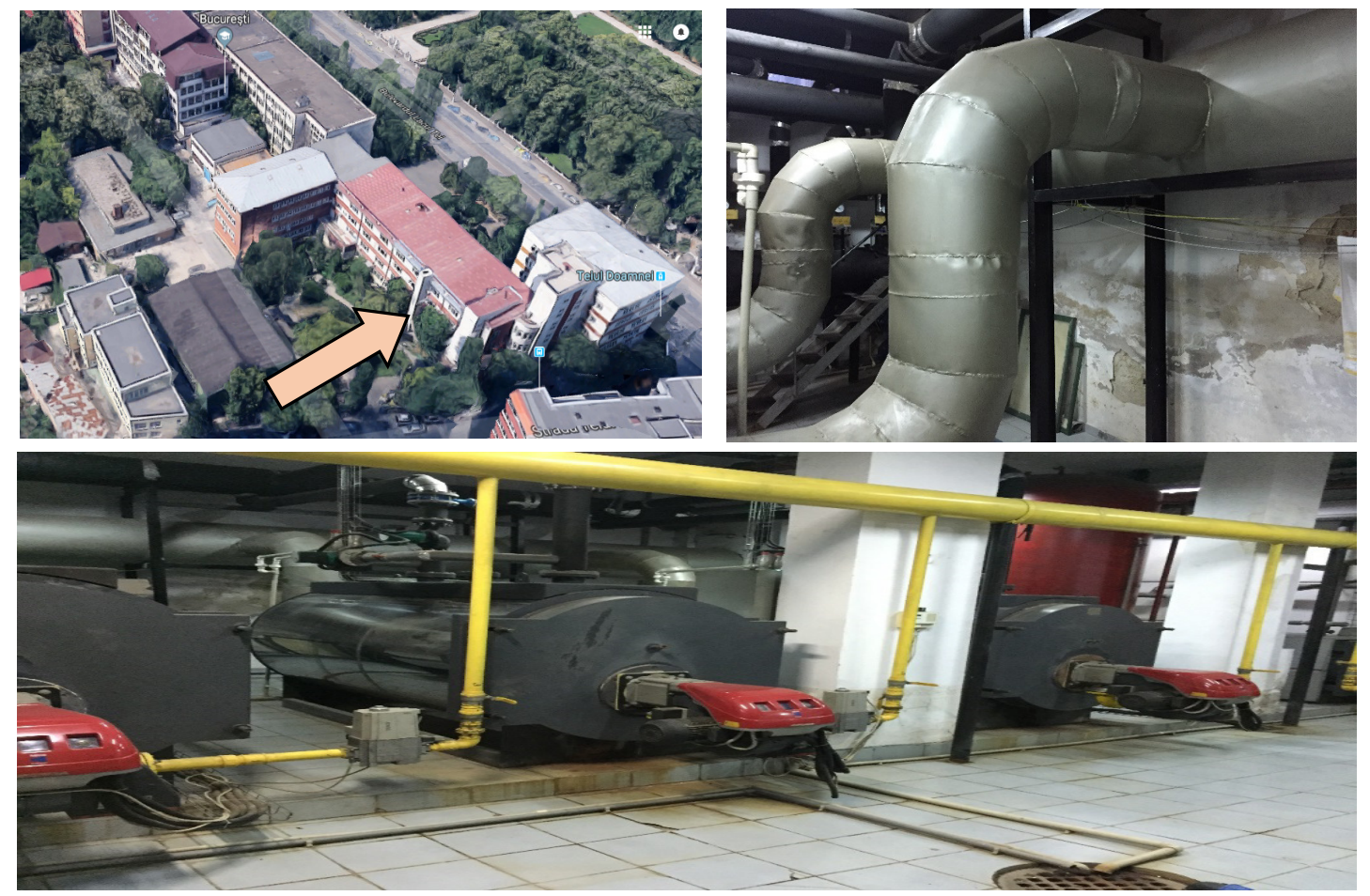

Fig.1 - Thermal plant. a) Boiler plant location b) Photo inside the thermal plant,

c) Noise protection solution for the chimney 


\section{Catalin Bailescu, Vlad Iordache}

The boiler chimney (Fig.1b) is made of metallic material, insulated with mineral wool and covered with gypsum. The boilers are placed on puffers and their own foundation. The three burners do not have sound absorption housing, and the pipe connections are made by metal bracelets. The heating installation does not have flexible connections to ducts of the boiler (thermal / gas / fluid). There is no other noise protection like sound attenuator at chimney (in pipe or in quarter-wave) or walls captured with mineral wool or/and plasterboard.

Five types of measurements were made for each thermal power plant:

- dimensions (room, equipment, windows, doors, chimney).

- gas pressure and temperature. $\mathrm{pg}=0.03$ [bar]; $\mathrm{Tg}[\mathrm{oC}]$;

- reverberation time inside the thermal plant (EDT, T20, T30);

- sound pressure level ,Lp [dB], and global weighted sound pressure level, LAeq [dBA] for all audible spectrum octaves $16 \mathrm{~Hz}, 31.5 \mathrm{~Hz}, 63 \mathrm{~Hz}, 125 \mathrm{~Hz}, 250 \mathrm{~Hz}, 500 \mathrm{~Hz}$, $1000 \mathrm{~Hz}, 2000 \mathrm{~Hz}, 4000 \mathrm{~Hz}, 8000 \mathrm{~Hz}$

- gas consumption for each thermal power: two indexes and time period

The burner stage control was set using the boiler control panel by selecting the desired step, as shown below. A number of 12 operating condition of the boiler are presented in Table 1. The first case is the situation where no equipment is working. These boilers have a circulating pump, which circulate water within the boiler to enhance boiler operation. To analyze the noise produced by these equipment, the burners of boilers were switched off. Cases 2-12 are situations in which burner operate simultaneously, at different power stages.

Table 1

Operating condition of the boiler

\begin{tabular}{|l|c|c|c|c|c|}
\hline Case [-] & Boilers pump [-] & Burner1 [-] & Burner2 [-] & Burner3 [-] & Burner4 [-] \\
\hline 1 & OFF & OFF & OFF & OFF & OFF \\
\hline 2 & OFF & STAGE 1 & OFF & OFF & OFF \\
\hline 3 & ON & STAGE 2 & OFF & OFF & OFF \\
\hline 4 & ON & OFF & OFF & STAGE 1 & OFF \\
\hline 5 & ON & OFF & OFF & STAGE 2 & OFF \\
\hline 6 & ON & STAGE 1 & OFF & STAGE 2 & OFF \\
\hline 7 & ON & STAGE 2 & OFF & STAGE 2 & OFF \\
\hline 8 & ON & STAGE 1 & OFF & STAGE 1 & OFF \\
\hline 9 & ON & STAGE 1 & STAGE 2 & OFF & OFF \\
\hline 10 & ON & STAGE 1 & STAGE 2 & STAGE 1 & OFF \\
\hline 11 & ON & STAGE 2 & STAGE 2 & STAGE 2 & OFF \\
\hline 12 & ON & STAGE 2 & STAGE 2 & STAGE 2 & STAGE 2 \\
\hline
\end{tabular}

For the fuel consumption measurement, the initial and final index of gas meter was recorded for a period of $1 \mathrm{~min}$. During this time the noise measurements were made inside the technical space. Before the actual measurements began, the gas temperature and pressure were recorded (Fig.2). 
Experimental analysis of the noise produced by burners inside a boiler plant in an educational building
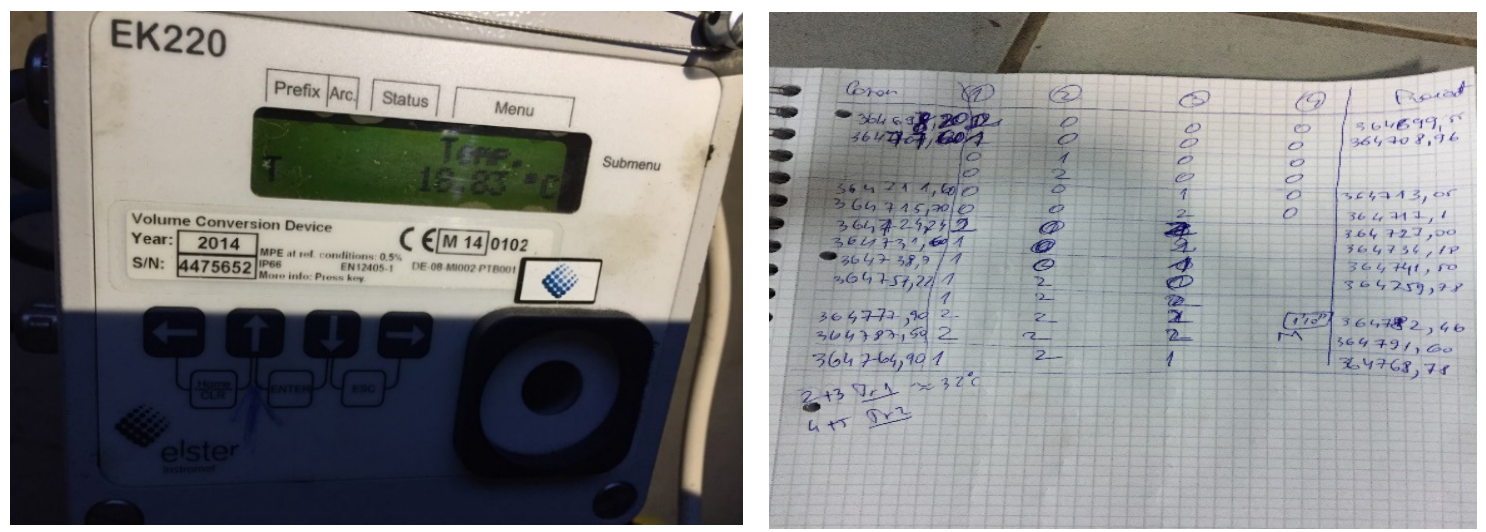

Fig.2 - Reading of gas index b) gas parameter

The measurement of the noise level was carried with a 2250 sound meter from Bruel\&Kjaer. The point from which the measurements were made is represented in Fig.3 with blue. This point was situated at the heights that the [9] standard established. The noise measurement was recorded at 1-meter distance from the burner, measured according to the norms. With red dot are the two main noise sources of the technical space (the two boilers burners that were on).

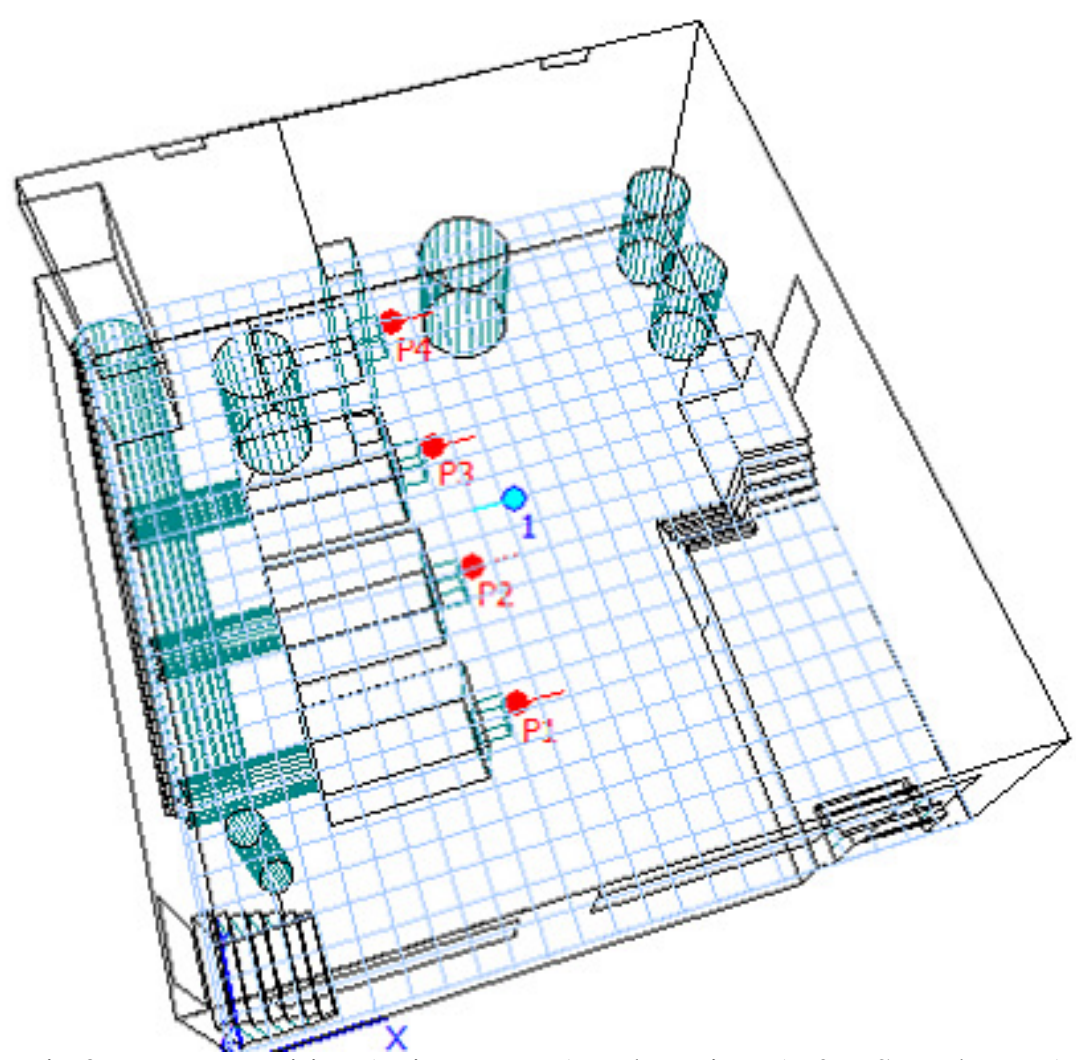

Fig.3 - Burner position (noise sources) and receiver (B\&K Sound meter) 
Catalin Bailescu, Vlad Iordache

The reverberation time was also measured using the same sound meter and a noise source, we record the decay curves for all frequency bands and the reverberation time is calculated by means of the sound meter software for all frequencies.

\section{The database and results}

The gas measurements and the real thermal power are presented in Table 2, calculated based on the gas consumption, which is the difference between the final index and the initial reading from the gas meter by one of the participants in the experiment.

Gas consumption and parameters

\begin{tabular}{|c|c|c|c|c|}
\hline Case [-] & Initial Index $\left[\mathrm{m}^{3}\right]$ & Final Index $\left[\mathrm{m}^{3}\right]$ & Consumption $\left[\mathrm{m}^{3}\right]$ & $\Phi_{\text {burner }}[\mathrm{kW}]$ \\
\hline 1 & 364698.20 & 364698.20 & 0.00 & 0.00 \\
\hline 2 & 367707.60 & 364708.96 & 1.36 & 794.00 \\
\hline 3 & 364698.20 & 364699.55 & 1.35 & 787.00 \\
\hline 4 & 364711.60 & 364713.05 & 1.45 & 847.00 \\
\hline 5 & 364715.70 & 364717.10 & 1.40 & 818.00 \\
\hline 6 & 364731.60 & 364734.18 & 2.58 & 1507.00 \\
\hline 7 & 364724.24 & 364727.00 & 2.76 & 1612.00 \\
\hline 8 & 364738.70 & 364741.00 & 2.80 & 1636.00 \\
\hline 9 & 364757.22 & 364759.78 & 2.56 & 1495.00 \\
\hline 10 & 364764.90 & 364768.78 & 3.88 & 2266.00 \\
\hline 11 & 364777.90 & 364777.90 & 4.56 & 2664.00 \\
\hline 12 & 364787.50 & 364787.60 & 4.10 & 2395.00 \\
\hline
\end{tabular}

The following formula was used to determine the actual thermal load of the boiler:

$\Phi_{\text {burner }}=\frac{I_{F}-I_{I}}{60} \cdot \frac{p_{g}+p_{0}}{p_{0}} \cdot \frac{T_{0}}{T_{g}} \cdot H_{i}$

where:

$\Phi_{\text {burner }}, \mathrm{kW}$, is real thermal power for 60 seconds;

$I_{F}, \mathrm{~m}^{3}$, and $I_{I}, \mathrm{~m}^{3}$, are the final index and initial read recording from the gas meter;

$H_{\text {I comb }}, \mathrm{kJ} / \mathrm{m}^{3} \mathrm{~N}$, is the low fuel calorific value, $H_{\mathrm{Icomb}}=35371.70\left[\mathrm{~kJ} / \mathrm{m}^{3} \mathrm{~N}\right]$;

$\mathrm{p}_{\mathrm{o}}$, bar, is the atmospheric pressure, $\mathrm{p}_{\mathrm{o}}=1.01325$ [bar]

$\mathrm{T}_{0}, \mathrm{~K}$, is the gas temperature under normal conditions, $\mathrm{T}_{0}=273.15[\mathrm{~K}]$

$\mathrm{Pg}$, bar, is the measured gas pressure,

$\mathrm{Tg}, \mathrm{K}$, is the measured temperature of methane gas

It can be seen from the Fig.4 that the noise level for the situation where pumps works (yellow) works is below $62 \mathrm{~dB}$ for each frequency. After starting burners, the noise level increases above $73 \mathrm{~dB}$ at $1000 \mathrm{~Hz}$ and is directly proportional to the thermal load. However, the norm is not exceeded for any of the operating scenarios. 
Experimental analysis of the noise produced by burners inside a boiler plant in an educational building

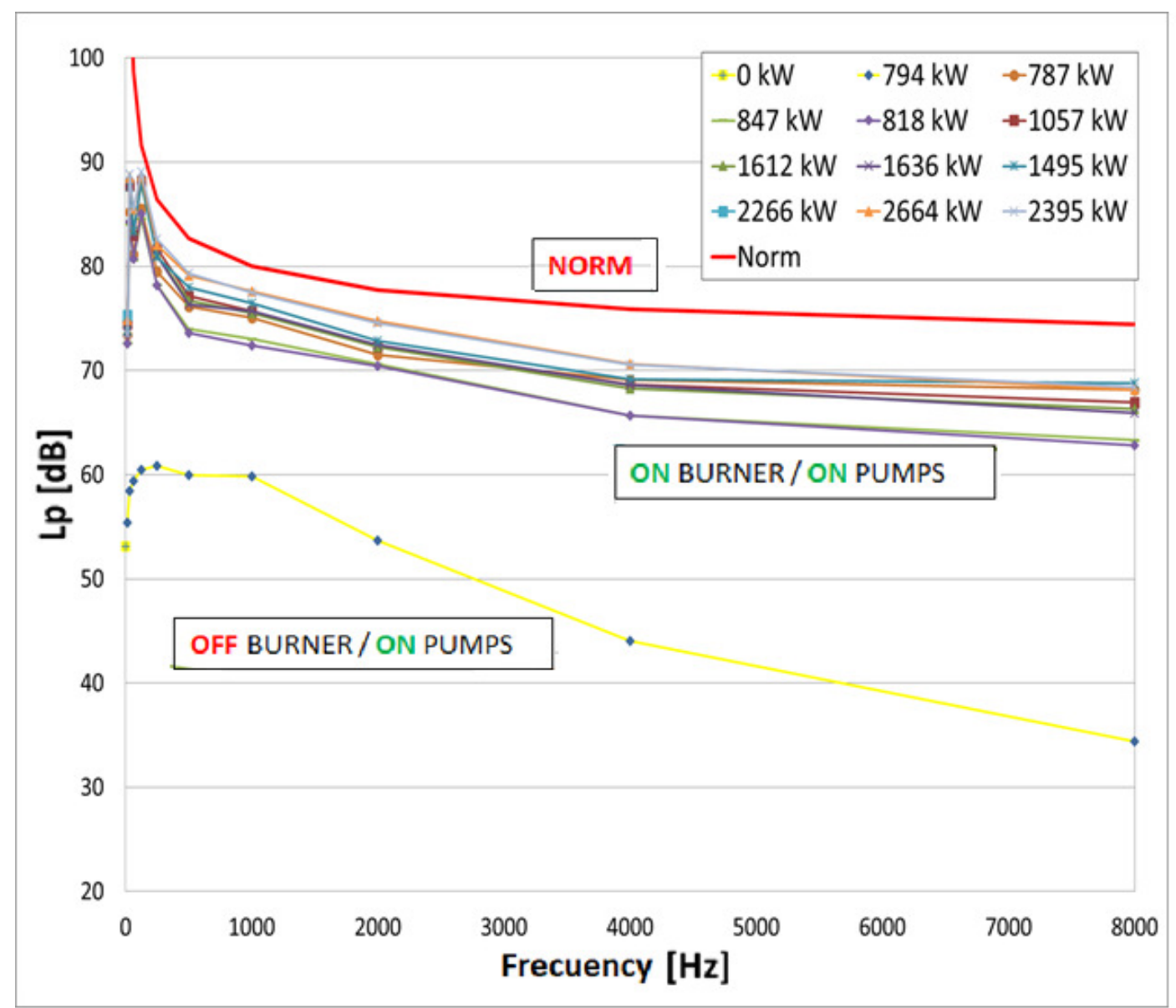

Fig.4 - Comparison between noise level on each frequency and Cz80 from norms

It is noticed that the noise level has different values depending on the frequencies. Another observation is that for higher frequencies the measurements of noise level have higher values compared to the low frequency noise level. From medium to high frequencies the noise level has a downward trend. There is a difference of up to $20 \mathrm{~dB}$ for the noise level measured at $1000 \mathrm{~Hz}$ compared to the noise level at $8000 \mathrm{~Hz}$.

Another noise level measurement collected was noise level, measured using the filter specified as the A-curve. In the Fig.5 has been compared global noise levels weighted after curve A for all 12 operating situations with the noise value from technical data sheet of boiler and the value imposed by [8]. 
Catalin Bailescu, Vlad Iordache

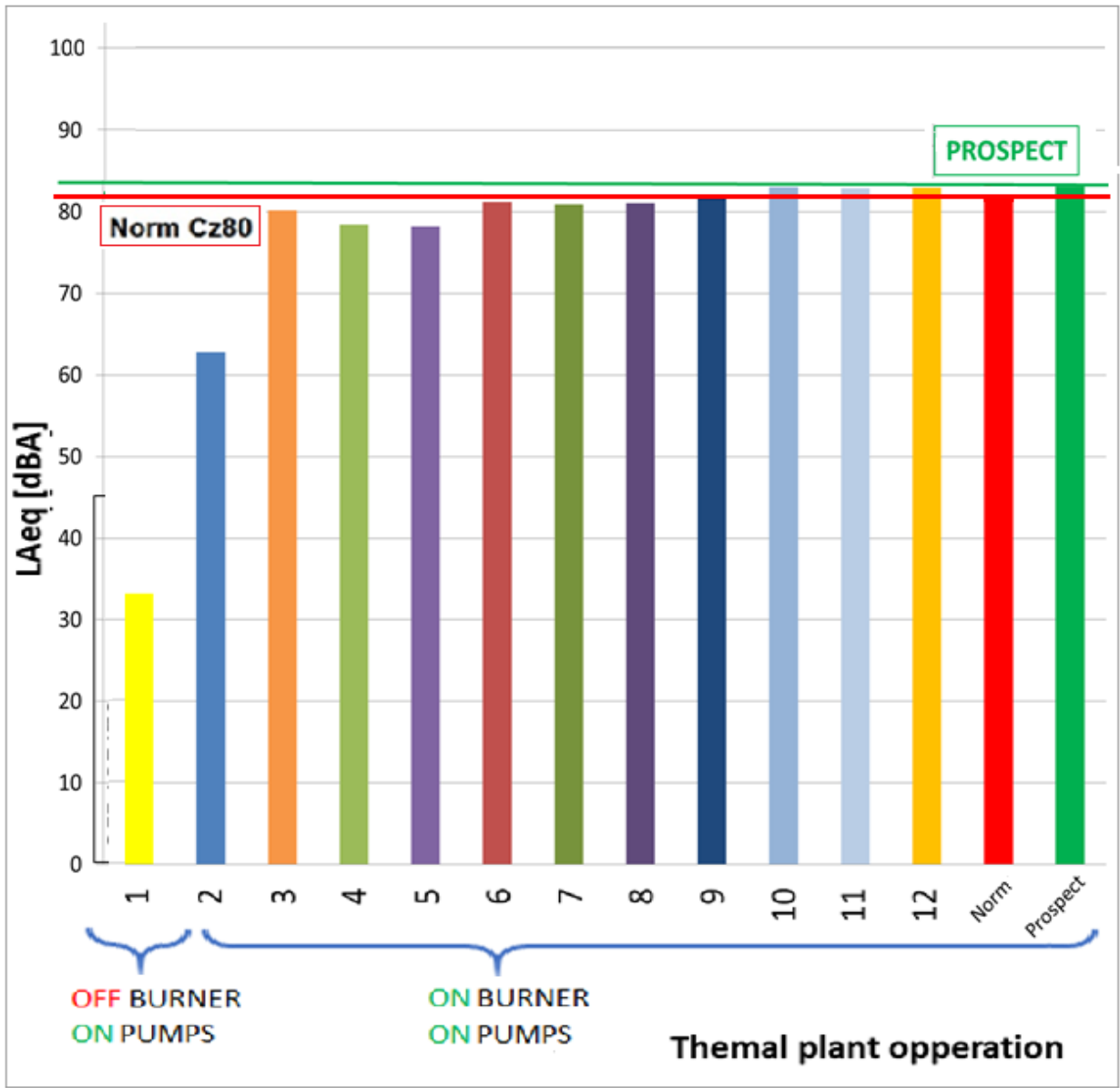

Fig.5 - Comparison between global weight equivalent noise level, boiler data sheet and Cz80 from norms

It is noticed that measurements for all operating conditions of the boilers don't exceed the value indicated from datasheet but is higher than $82 \mathrm{~dB}(\mathrm{~A})$ from norm [8]. The conclusion is that this thermal plant needs an acoustic refurbishment to full fill today's acoustic norms because the equivalent noise level is higher than the values from the norm.

In the figures below, the dependence between the noise level for each frequency and the thermal load of the burner will be studied. From Fig.6a it is observed that at low frequency the noise level has value between $63 \mathrm{~dB}$ and $83 \mathrm{~dB}$. An increasing tendency is observed in both graphs, thus validating the prediction models [1] and [2], which have as main parameter for predicting noise level the thermal load. The same increasing trend is also noticeable in Fig.6b. For average frequencies, the noise level is between $60 \mathrm{~dB}$ and $79 \mathrm{~dB}$. At all frequencies, the noise level is not well fitted.

The coefficient of determination, R2, is represented in Fig.6 and this value is used to analyse how differences in one variable can be explained by a difference in a second variable. Subsequently, $\mathrm{R}$ is calculated and corresponds to correlation coefficients, but for nonlinear variation tendencies. 
Experimental analysis of the noise produced by burners inside a boiler plant in an educational building

In acoustics, phenomena vary depending on the frequencies studied, so the rules are broken down at each frequency. And in this study, we looked at the dependence between Lp and $\Phi$ burner for different frequencies.
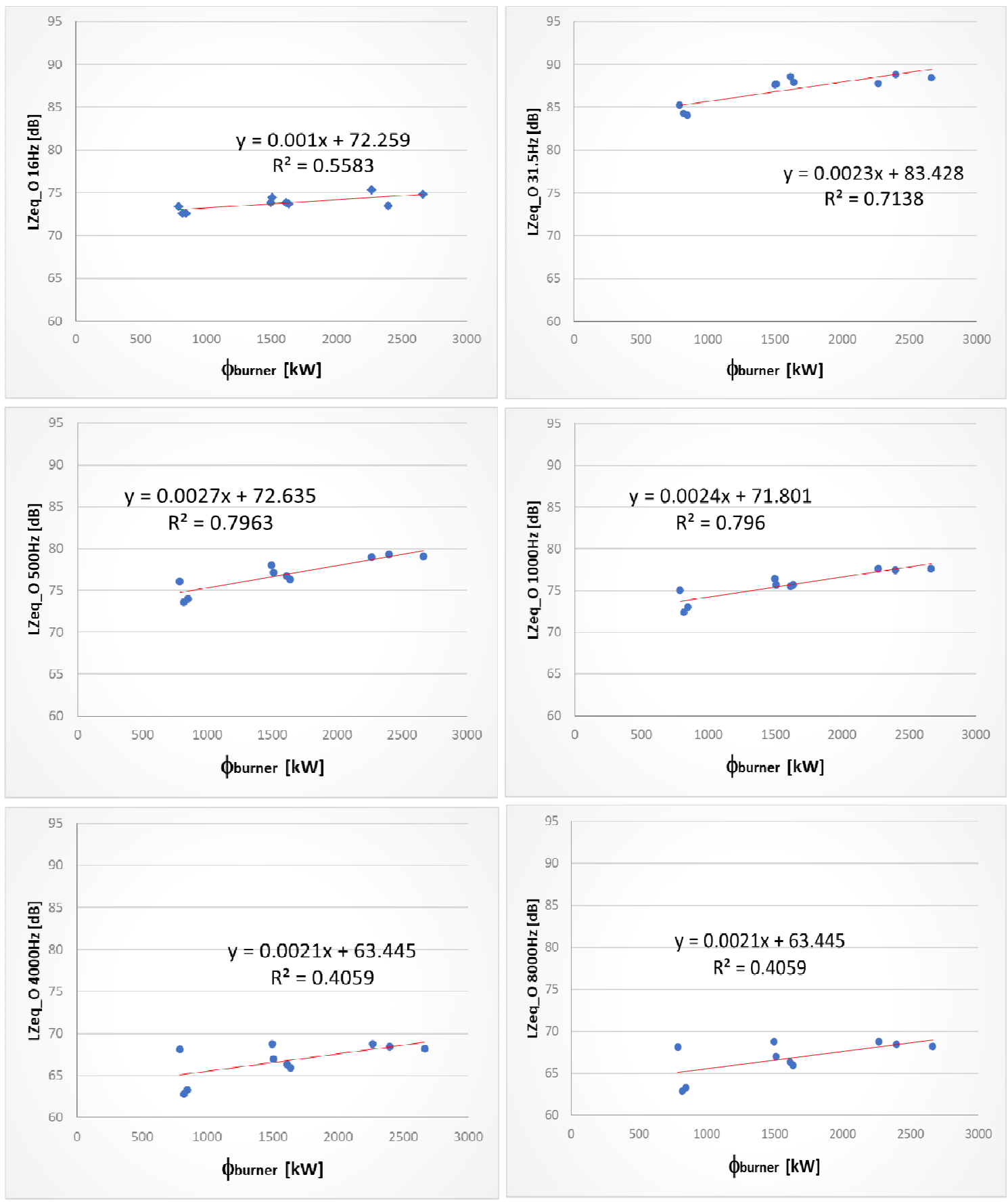

Fig.6 - Recorded sound pressure level based on thermal power for a) low frequencies $(16 \mathrm{~Hz}, 31.5 \mathrm{~Hz})$;

b) medium frequencies $(500 \mathrm{~Hz}, 1000 \mathrm{~Hz})$ and c) high frequencies $(4000 \mathrm{~Hz}, 8000 \mathrm{~Hz})$ 
Fig.7 depicts the relationship between equivalent noise level (LAeq) and thermal power $\Phi$ burner. From this graph we can see the increasing tendency of the equivalent noise level depending on the thermal load of the boiler. This increase validates the prediction models from the literature, which have their component and thermal load, as the main parameter.

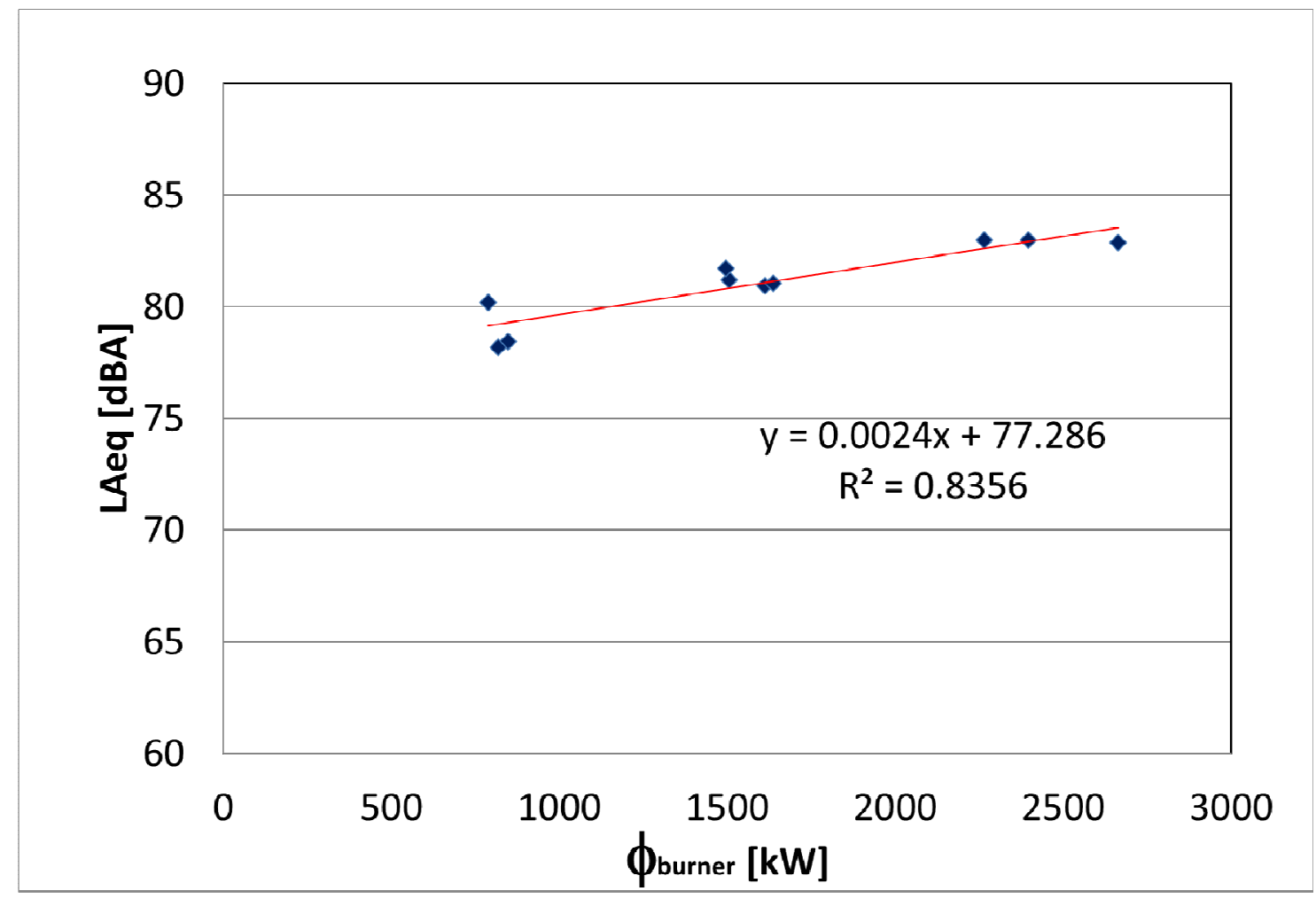

Fig.7 - Equivalent noise level based on actual thermal power, equation and R2

Further, we study the adaptability of predictive models of noise level for the analysed thermal plant. Cyssau's model [1], as well as Hamayon's model [2], predicts the global weighted equivalent noise level. These values were compared with the measurements obtained during the experiment to highlight if the errors of the two models are centred in 0 and if they are adapted for modern thermal power plants and new equipment.

Compared to our measurements, Cyssau's model [1] has an error between $11 \mathrm{dBA}$ (for $2000 \mathrm{~kW}$ ) and $13 \mathrm{dBA}$ (for $700 \mathrm{~kW}$ ), higher than $10 \mathrm{dBA}$ declared by the author (Fig.8). The errors of the Cyssau's model compared to our experimental data are not centred in zero. We conclude that Cyssau's model is not suited for today's thermal powers and for the new thermal generation equipment. 
Experimental analysis of the noise produced by burners inside a boiler plant in an educational building

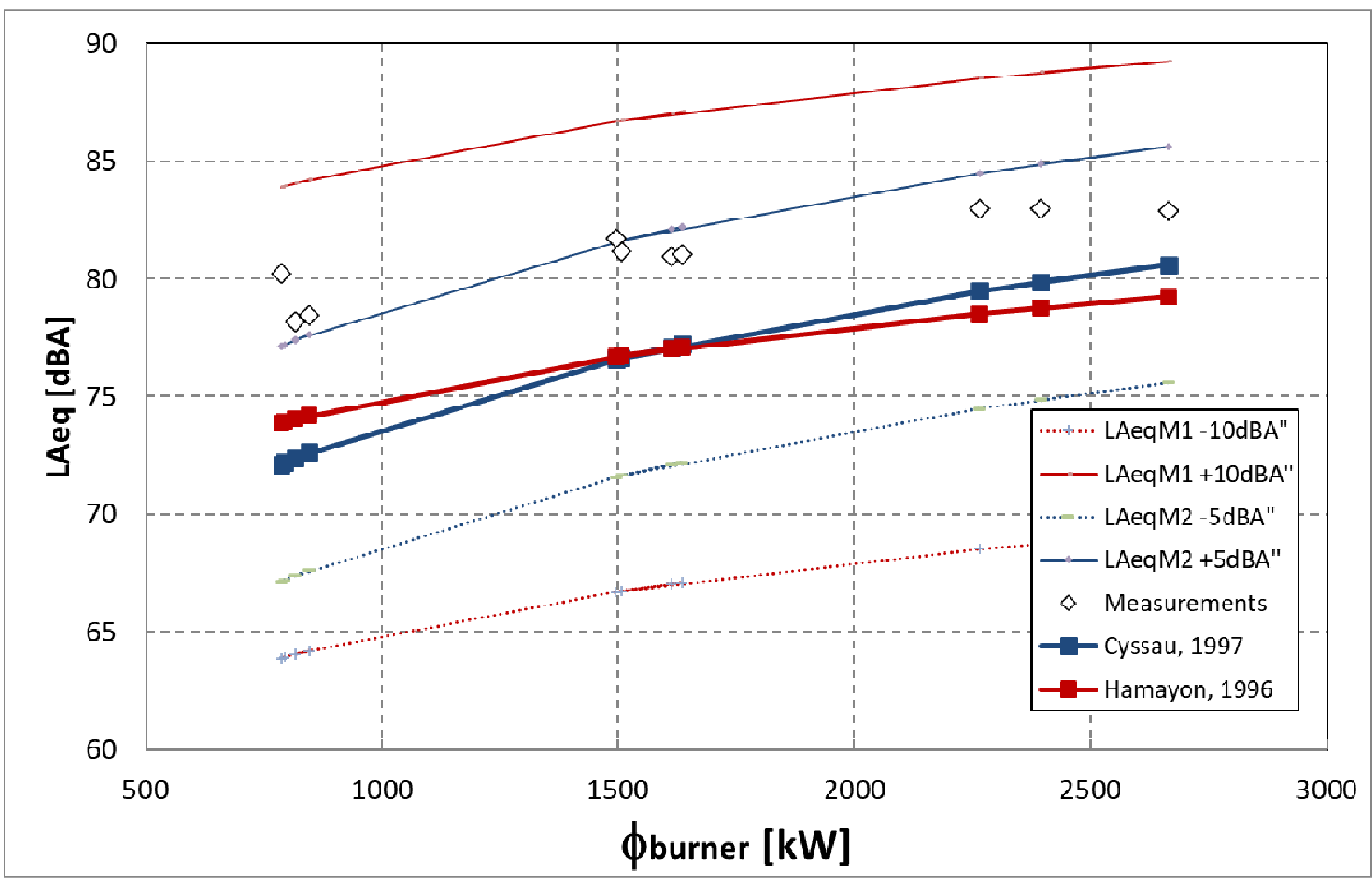

Fig.8 - Comparison between measured and predicted noise level values, Cyssau [1] and Hamayon[2]

Hamayon's model [2] present slightly higher errors: between $15 \mathrm{dBA}$ (for $800 \mathrm{~kW}$ ) and $10 \mathrm{dBA}$ (for $2000 \mathrm{~kW}$ ), higher than 5dBA declared by the author. The graph from Fig. 8 shows that Hamayon's model predicts lower noise levels than those measured for 8 different thermal powers, and the lower and upper limit of its error is far from the measurements made during the experiment. Similar to Cyssau's model, Hamayon's model present errors that are not centred in zero. In conclusion Hamayon's model is not suited either, for today's thermal powers and for the new thermal generation equipment.

Therefore there is need for an adaptation of the noise prediction models to today's thermal conditions (larger thermal power stations, noisier equipment and automation control).

\section{Conclusions}

There is a reasonable consensus that the equipment that produces a high noise level in a thermal plant is the burner, and not pumps or other components of the heating system.

From the analyzes made in comparison with the datasheet, there were revealed that they produce a lot of noise but do not exceed the values given by the producer of the burner, which indicate a correct operation of the equipment. Also in this study were highlighted that the measurements of the noise levels exceed the maximum value indicated in the norm [8]. Out of the 11 operating situations of the burners in 4 were 
Catalin Bailescu, Vlad Iordache

found exceedances of the value of $82 \mathrm{dBA}$. For case 12, the highest noise level was recorded, with $2 \mathrm{dBA}$ higher than the value imposed by the norm.

The increasing tendency of the equivalent noise level depending on the thermal load of the boiler is another very useful conclusion for designers to estimating the noise level. So when a building requires a higher installed thermal load, designers need to take into consideration the higher equivalent noise level generated in the thermal plant room in order to ensure the comfort parameters indoors.

The acuracy of the existing prediction models of the noise level inside the thermal plant room, is higher than the error characterizing the models. Therefore there is need for an adaptation of the noise prediction models to today's thermal conditions (larger thermal power stations, noisier equipment, and automation control). New prediction model should be based on new experimental campaign for the new type of thermal plants and the new installed equipment.

\section{Reference}

[1] Cyssau, R., Palenzuela, D. \& Francoise E. (1997). Bruit des equipments. Collection des guides de l'AICVF. France: Ed PYC Edition livres

[2] Hamayon, L. (2001). Reussir l'acoustique d'un batiment. France: Ed. Le Montieur

[3] United States Building Council (2009). LEED ${ }^{\mathrm{TM}}$, Guide of reference, Version: 3.0. USA: Ed. USBC.

[4] American National Standard Acoustical Performance Criteria (2002). Performance Criteria, Design. Requirements, and Guidelines for Schools. ASA S12.60 PART 1. USA

[5] Ocupational Safety and Health Standards (2003). Occupational noise exposure. 29 CFR 1910.25. USA

[6] European Parliament and of the Council (2003). Directive 2003/10/CE on the minimum health and safety requirements regarding the exposure of workers to the risks arising from physical agents. Eurpean Union: Ed. European Parliament and of the Council

[7] International Organization for Standardization (2009). Acoustics- Determination of occupational noise exposure- Engineering method. EN ISO 9612:2009, Switzerland

[8] Monitorul oficial al Romaniei (2012). Normativ privind acustica în construcții și zone urbane C125-2013. Romania: Guvernul Romaniei. Ministrul dezvoltării regionale şi turismului. (romanian)

[9] International Organization for Standardization. (2017). Acoustics - Description, measurement and assessment of environmental noise - Part 2: Determination of sound pressure levels. ISO 1996-2:2017. USA

[10] Vianna, K., Cardoso, M. \& Rodrigues, R. (2015). Noise pollution and annoyance: An urban soundscapes study, Noise Health. 17(76): 125-133. doi: 10.4103/1463-1741.155833

[11] Tandel, B.N, \& Jem, M. (2013). Assessment and Mlr Modelling Of Urban Traffic Noises at Major Arterial Roads of Surat. Journal of Environmental Research and Development. 2013; 7(4A):1703-1709.

[12] Méline, J., Van Hulst, A., Thomas, F., Karusisi, N \& Chaix, B. (2013). Transportation noise and annoyance related to road traffic in the French RECORD study. Int J Health Geogr. 2013;12:44.

[13] Brambilla, G., Gallo. V, \& Zambon. G. (2013). The Soundscape quality in some urban parks in Milan, Italy. Int J Environ Res Public Health. 2013;10:2348-6 
Experimental analysis of the noise produced by burners inside a boiler plant in an educational building

[14] Iordache, V. \& Catalina, T. (2013). Experimental investigation on the sound pressure level for a high thermal capacity burner during a running cycle. JOURNAL Applied Acoustics, Volume: 74 Issue: 5 Pages: 708-717

[15] Tacutu, L., Pocola, A., Balan, M. \& Iordache, V. (2017). Acoustic measurements for two configurations of acoustic casings with applications on ambient noise pollution, Conference: 8th International Conference on ENERGY and ENVIRONMENT (CIEM). 19-20 October 2017 (pp. 129133). Bucharest, Romania: International Conference on Energy and Environment. 